Total Quality Management \& Business Excellence

\title{
Synergies between critical success factors of Lean Six Sigma and public values
}

\section{Fernando Juliani \& Otávio José de Oliveira}

To cite this article: Fernando Juliani \& Otávio José de Oliveira (2017): Synergies between critical success factors of Lean Six Sigma and public values, Total Quality Management \& Business Excellence, DOI: 10.1080/14783363.2017.1383153

To link to this article: https://doi.org/10.1080/14783363.2017.1383153

册 Published online: 09 Oct 2017.

Submit your article to this journal

Џlll Article views: 117

View Crossmark data \lceil 


\title{
Synergies between critical success factors of Lean Six Sigma and public values
}

\author{
Fernando Juliani* and Otávio José de Oliveira
}

Production Engineering Department, UNESP - Univ Estadual Paulista, São Paulo, Brazil

\begin{abstract}
The purpose of this paper is to identify synergies between the relevant critical success factors (CSFs) of Lean Six Sigma (LSS) and the public values (PVs) introduced into public service management. Firstly, the approach taken by authors in presenting research was to analyse recent literature review emphasizing on the relevant CSFs for LSS application and PVs introduced into public service management. Afterwards, a new analysis highlighting the synergies between these two approaches was performed. Based on the nine more relevant CSFs for LSS application and the seven PV dimensions, five significant synergies between the two approaches were identified in the recent literature. The presenting research should assist public managers of adopting the LSS practice, and guide researchers in the development of surveys aimed at the application of this methodology in public organisations in general, enabling a better quality of services provided to citizens.
\end{abstract}

Keywords: Lean Six Sigma; critical success factors; public values; public service management; synergies

\section{Introduction}

Important welfare factors for the society are usually related to the quality of social services received by citizens and executed by public organisations. Meeting the customer needs by providing quality services is one of the premises of Lean Six Sigma (LSS) philosophy, and should be the main objective of the public service organisations.

The LSS methodology has been proven effective in solving specific business problems facing the industry and has provided benefits such as easy dissemination of knowledge, great return on investment, scope limitation, process complexity reduction and addressing of problems (Duarte, Montgomery, Fowler, \& Konopka, 2012).

On the other hand, the LSS application in public organisations is a difficult task, since the organisational structure is complex as well as its administration, which may be exercised directly by local, state or federal governments, or indirectly, by foundations or public companies (Shahin, Attafar, \& Samea, 2012). In addition, profit is not a motivating factor within the public sector and its budget is directly influenced by the political system, being structured to encourage the use of allocated funds rather than reducing costs or generating profits (Meza \& Jeong, 2013).

Nevertheless, the combination of LSS can be beneficial to the public sector, providing different approaches to smaller and larger projects and organisations, and ideas of either of the two methods can be employed to enhance the other (Assarlind, Gremyr, \& Bäckman, 2013). The reduction of waste, for example, can direct the Six Sigma projects, while the Define-Measure-Analyze-Improve-Control (DMAIC) cycle can provide structure to Lean projects. And considering most of the public sector resources are obtained from

${ }^{*}$ Corresponding author. Email: frdjuliani@gmail.com 
the government, avoiding waste in a limited timeframe is crucial for nonprofits organisations (Cheng \& Chang, 2012).

The success of LSS implementation is highly dependent on the extent to which the specific properties of the organisation are addressed (Werner Timans, Ahaus, van Solingen, Kumar, \& Antony, 2014). The implementation of LSS requires essential elements known as critical factors success without which any continuous improvement initiative stands little chance of success (Antony, Krishan, Cullen, \& Kumar, 2012). As the public sector regards specifically, meeting the values that guide public service management is relevant due to the fact that LSS is an industry-oriented methodology. Therefore, the adoption of LSS philosophy in public service organisations requires a custom deployment.

Considering this customization can be initiated by the pursuit of the main critical success factors (CSFs) of LSS identified in the literature and their adequacy to the public sector principles, the purpose of this paper is to identify synergies between relevant CSFs of LSS and public values (PVs) introduced in the public sector to assist public managers of adopting the LSS practice and to guide researchers in the development of surveys focusing on the application of LSS principles in public organisations, aiming to improve the quality of services provided to citizens.

The following section gives an overview of the theory on which this paper was based. Subsequently, the research method used in this article is presented, covering the adopted research parameters and database used. After that, potential synergies between CSFs of LSS and PVs are described. In the last section, the findings of the study are presented, highlighting their scientific contribution and proposals for future studies.

\section{Theoretical review}

Focusing on the application of LSS principles in public organisations, it is mandatory to describe LSS and its CSFs, as well as public service management and PVs.

\subsection{LSS and its CSFS}

The LSS methodology is briefly and well defined by Duarte et al. (2012) as being a combination of two methodologies that have proven to be a powerful tool for driving efficiency and effectiveness process, with the Lean focusing on the process speed and the Six Sigma focusing on the accuracy. According to Tenera and Pinto (2014), this integration was achieved through factors such as the junction of methods and principles of the DMAIC cycle, joint continuous improvement, reduction of both production defects and process variability, simplification and standardization of processes and waste reduction. Having a standard improvement model such as DMAIC is extremely helpful, because it provides the organisation with an improvement roadmap (Wang \& Chen, 2012).

In addition to the features described hereabove, Parris (2013) states that both Lean and Six Sigma require paradigm shifts from the acceptance of the problems encountered and the poor performance to the disclosure and resolution of problems, always pursuing the excellence through equipped workforce able to perform the improvements. For Laureani and Antony (2017), merging tools and principles from both Lean and Six Sigma, the product quality, process speed, costs and customer satisfaction are improved.

According to Assarlind and Aaboen (2014), it is common to identify the CSFs in studies of companies that have adopted Six Sigma, Lean and LSS. The importance of the CSFs definition for the application of LSS methodology is to increase the probability 
of success, reducing costs and avoiding disillusionment with continuous improvement programs (Meza \& Jeong, 2013). The main CSFs found in the recent literature are illustrated in Table 1.

Exploring the CSF literature on LSS implementation, two major aspects can be distinguished (Psychogios \& Tsironis, 2012): the management-oriented aspect, associated with factors such as business strategy, customer focus and project management; and the humanresources-oriented, which is related to issues such as commitment and leadership, qualitydriven culture, training and education and teamwork.

\subsection{Public service management and PVs}

In the scientific community, there are several definitions to describe service. However, according to Aurich, Mannweiler, and Schweitzer (2010), there is not a single acceptable definition. There is a consensus as to its characterization covering the intangibility, heterogeneity, simultaneity of production and consumption, and perishability. Bilouseac, Zaharia, and Scutariu (2012) believe that the public service is specifically an activity conducted or authorized by an administrative authority which is intended to meet the requirements of community members.

Most of the public services are provided by local governments, and inefficiencies in the performance of these services can have serious consequences for the social welfare of citizens (Cuadrado-Ballesteros, García-Sánchez, \& Prado-Lorenzo, 2012). Many governments have implemented total quality management and similar approaches in their activities and processes as a way to achieve effectiveness, efficiency and flexibility in the public sector. However, it is essential to preserve the values inherent in the public sector in order to leverage the strengths of governance at various levels, as defined by Conteh (2012).

According to Bannister and Connolly (2014), the definition of public value is directly related to the other two expressions: ethics and principles. Bruns (2014) argues that creating public value is a decision-making process that aims to identify, prioritize and assume if a program or a specific public policy is important for citizens under certain circumstances. Andersen, Jørgensen, Kjeldsen, Pedersen, and Vrangbæk (2012) classified PVs in seven dimensions and items which were theoretically seen as a part of each dimension, as illustrated in Table 2.

Table 1. Main CSFs of LSS from recent literature.

\begin{tabular}{|c|c|c|c|c|c|c|c|}
\hline \multirow[b]{2}{*}{ CSFs of LSS } & \multicolumn{7}{|c|}{ Authors } \\
\hline & A11 & $\mathrm{A} 2$ & A3 & A4 & A5 & A6 & A7 \\
\hline Project management and selection & $\mathrm{x}$ & $\mathrm{x}$ & $\mathrm{x}$ & $\mathrm{x}$ & $\mathrm{x}$ & $\mathrm{x}$ & $\mathrm{x}$ \\
\hline Training and education & $\mathrm{x}$ & $\mathrm{x}$ & $\mathrm{x}$ & $\mathrm{x}$ & $\mathrm{x}$ & $\mathrm{x}$ & $\mathrm{x}$ \\
\hline Management commitment and leadership & $\mathrm{x}$ & $\mathrm{x}$ & $\mathrm{x}$ & $\mathrm{x}$ & $\mathrm{x}$ & $\mathrm{x}$ & $\mathrm{x}$ \\
\hline Business strategy & $\mathrm{x}$ & $\mathrm{x}$ & $\mathrm{x}$ & $\mathrm{x}$ & & & \\
\hline Communication & $\mathrm{x}$ & & $\mathrm{x}$ & $\mathrm{x}$ & $\mathrm{x}$ & $\mathrm{x}$ & \\
\hline Customer focus & $\mathrm{x}$ & $\mathrm{x}$ & $\mathrm{x}$ & & & $\mathrm{x}$ & $\mathrm{x}$ \\
\hline Organisational culture & $\mathrm{x}$ & & & $\mathrm{x}$ & & $\mathrm{x}$ & $\mathrm{x}$ \\
\hline Selection of staff & $\mathrm{x}$ & $\mathrm{x}$ & & $\mathrm{x}$ & $\mathrm{x}$ & & \\
\hline Organisational infrastructure & $\mathrm{x}$ & $\mathrm{x}$ & $\mathrm{x}$ & & & $\mathrm{x}$ & \\
\hline
\end{tabular}

Notes: A1: Laureani and Antony (2012); A2: Bakar, Subari, and Daril (2015); A3: Manville, Greatbanks, Krishnasamy, and Parker (2012); A4: Hilton and Sohal (2012); A5: Jeyaraman and Teo (2010); A6: Timans, Antony, Ahaus, and van Solingen (2012); A7: Psychogios, Atanasovski, and Tsironis (2012) 
Table 2. The public value dimensions and related items. Adapted from Andersen et al. (2012).

\begin{tabular}{|c|c|}
\hline Dimension & Items \\
\hline The public at large & $\begin{array}{l}\text { Accountability towards society in general } \\
\text { Public insight and transparency }\end{array}$ \\
\hline Rule abidance & $\begin{array}{l}\text { Judicial values/due process } \\
\text { Being loyal to rules }\end{array}$ \\
\hline Budget keeping & $\begin{array}{l}\text { Having economic awareness } \\
\text { Stay within budget as motive }\end{array}$ \\
\hline Professionalism & $\begin{array}{l}\text { Independent professional standards } \\
\text { Having professional drive } \\
\text { Professional commitment as a motive }\end{array}$ \\
\hline Balancing interests & $\begin{array}{l}\text { Political loyalty } \\
\text { Being able to interpret political climate } \\
\text { Balancing interests } \\
\text { Make networks }\end{array}$ \\
\hline Efficient supply & $\begin{array}{l}\text { High productivity } \\
\text { Business-like operations }\end{array}$ \\
\hline User focus & $\begin{array}{l}\text { Satisfy immediate needs of users } \\
\text { User democracy } \\
\text { Good relations to users as motive }\end{array}$ \\
\hline
\end{tabular}

Jørgensen and Rutgers (2015) found that PVs have become increasingly important in the public administration study since the beginning of the twenty-first century. Furthermore, a growing number of governments and public organisations have adopted good governance codes based on a set of universal PVs to provide a firm basis for their actions (Jørgensen \& Sørensen, 2013).

The search for solutions to public sector problems has aroused the great interest of researchers to measure not only the service quality, but also the quality of people's life and improvements in the processes of governance (Gonzalez, Carcaba, Ventura, \& Garcia, 2011). The aim of this paper is to assist public managers and guide researchers focusing on the application of LSS principles in public organisations, once there are still a few researches on LSS application in this area, as stated in (Cheng \& Chang, 2012).

\section{Research method}

The research was conducted through queries performed utilising the Scopus database search engine, which is probably currently the best tool available for electronic literature search (Tukker, 2013). It provides access to most important scientific articles published in the following journals, among other publishers: Elsevier (www.sciencedirect.com), Emerald (www.emeraldinsight.com), Taylor \& Francis Online (www.tandfonline.com), Springer (www.springerlink.com) and Wiley (www.wiley.com). The objectives, how the research was carried out and the results are synthetized in Table 3. Firstly, the approach taken by authors in presenting research was to analyse recent literature review emphasising on the relevant CSFs for LSS application (CSFs related to Lean or to Six Sigma isolated were not considered in the analysis). For this purpose, all the articles in the English language published in peer-reviewed journals containing the words 'Lean Six Sigma' or 'Lean Sigma' and 'Critical Success Factors' in the title, in the abstract or in the keywords are reviewed. Editorials, books, chapters and reviews are not considered in the analysis. This study covers journal articles published between 2010 and 2015, reviewing the current state of the art. The search fields and the values used are illustrated in Table 4. 
Table 3. The research method synthetized.

\begin{tabular}{lcc}
\hline Objective & How & Results \\
\hline $\begin{array}{c}\text { Identifying the most relevant CSFs } \\
\text { of LSS }\end{array}$ & $\begin{array}{c}\text { Searching in the recent theory } \\
\text { through Scopus database } \\
\text { Identifying principles or values of } \\
\text { the public sector } \\
\text { purposed by some authors } \\
\text { through Scopus database } \\
\begin{array}{c}\text { Identifying possible synergies } \\
\text { between LSS and public sector } \\
\text { based on CSFs and PVs identified }\end{array}\end{array}$ & $\begin{array}{c}\text { Neane most relevant CSFs } \\
\text { were identified } \\
\text { through Scopus database } \\
\text { the public sector were } \\
\text { identified }\end{array}$ \\
\hline
\end{tabular}

Table 4. Search filters and values used in the research of the most relevant CSFs of LSS.

\begin{tabular}{lc}
\hline Scopus search fields & Values \\
\hline Article title, Abstract or & 'Lean Six Sigma' OR 'Lean Sigma' AND 'Critical Success \\
Keywords & Factors' \\
Period & $2010-2015$ \\
Language & English \\
Document type & Articles \\
Results & 17 (considered only the 7 most cited papers) \\
\hline
\end{tabular}

The criterion for the selection of the PVs which constituted the mapping proposed in this study was the degree of universality of each one, based on both multi-dimensional classification proposed by Andersen et al. (2012) and scientific papers published in recent years (Andersen, Jørgensen, Kjeldsen, Pedersen, \& Vrangbaek, 2013; Bryson, Crosby, \& Bloomberg, 2014; de Graaf, Huberts, \& Smulders, 2014; Jørgensen \& Sørensen, 2013; Van der Wal, Nabatchi, \& de Graaf,2014). The seven PVs covered in this study were illustrated in Table 2.

Afterwards, a new analysis highlighting the synergies between CSFs for LSS application and PVs introduced into public service management was performed. In order to identify synergies between these two approaches, all the articles in the English language published in peer-reviewed journals containing keywords that identified CSFs, PV dimensions and items of the PV dimensions were taken into account. It was used search terms that are specific rather than general to make the search as targeted as possible. As in the first analysis, editorials, books, chapters and reviews are not considered, being covered journal articles published between 2010 and 2015. The field codes, operators and keywords used in the queries are shown in the Appendix. The search fields and the values used are illustrated in Table 5.

The criteria applied for the selection of articles used to exemplify the identified synergies was the number of citations and the applicability of research done in the public service management.

\section{Synergies between LSS and PVs}

In this study, the identification of synergies comprises the junction of relevant aspects for the application of a methodology to a particular model of administration focusing on better performance management than that occurred in isolation. Key factors for successful 
Table 5. Search filters and values used in the research of possible synergies between CSFs of LSS and PVs of the public sector.

\begin{tabular}{lc}
\hline Scopus search fields & Values \\
\hline Keywords & {$[\mathrm{PV}$ term] AND [CSF term] (described in the Appendix) } \\
Period & $2010-2015$ \\
Language & English \\
Document type & Articles \\
Results & By synergy (Figure 1) \\
\hline
\end{tabular}

application of LSS methodology in organisations are entitled CSFs. Aspects related to ethics and principles which characterize the public service management have recently been linked to the term public value.

From the literature review, it can be claimed that LSS can provide benefits to the public service management presenting synergies with the PVs introduced into the public sector. This analysis is not exhaustive and was intended to point out where at least four relevant CSFs of LSS overlap four significant public value dimensions, resulting in five significant synergies between the two approaches, as illustrated in Figure 1.

Business strategy, related to main CSFs of LSS, and efficient supply, linked to public value dimensions, can be highlighted because both are in the most cited group twice. In Figure 2, it is possible to identify, more clearly, other possible synergies between CSFs of LSS and PVs: project management and selection with budget keeping and efficient supply; Training and education with efficient supply and user focus; Business strategy with rule abidance, efficient supply and user focus; Communication with rule abidance and user focus; Customer focus with user focus and Selection of staff with efficient supply.

Among the 63 queries performed in the Scopus database (they can be view in the Appendix), only one presented null result, suggesting that there is no synergy between organisational infrastructure and professionalism. The five correlations highlighted in

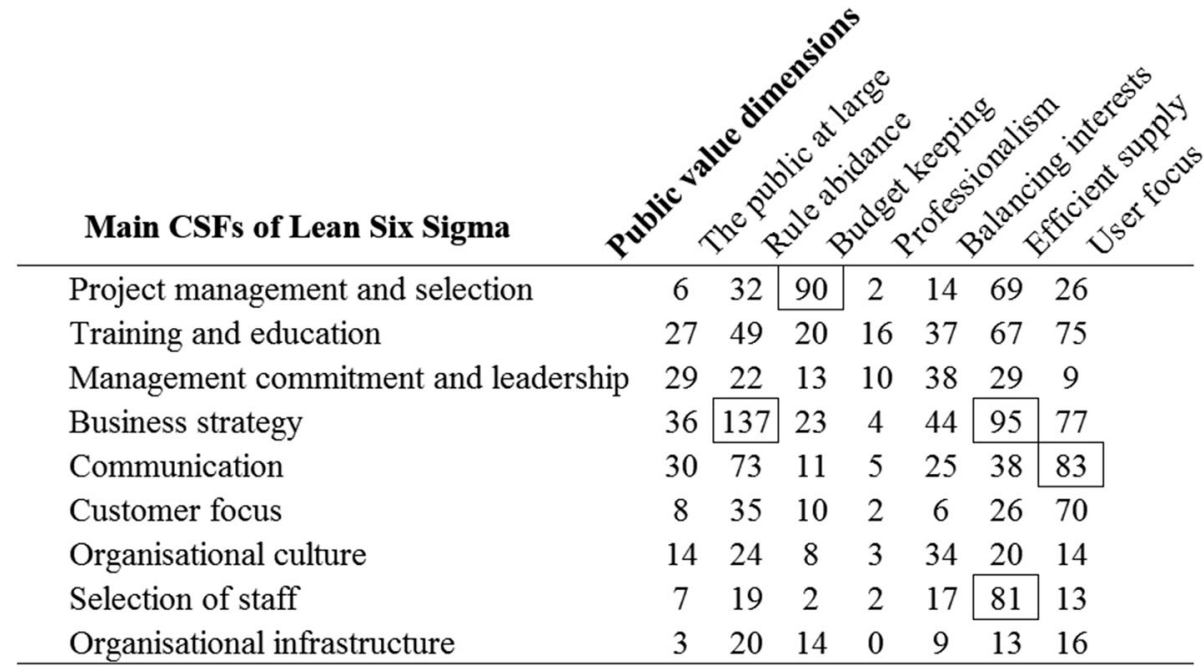

Number of articles found

Figure 1. Number of articles where possible synergies between the two approaches can be found. The highlighted items are covered in this study. 

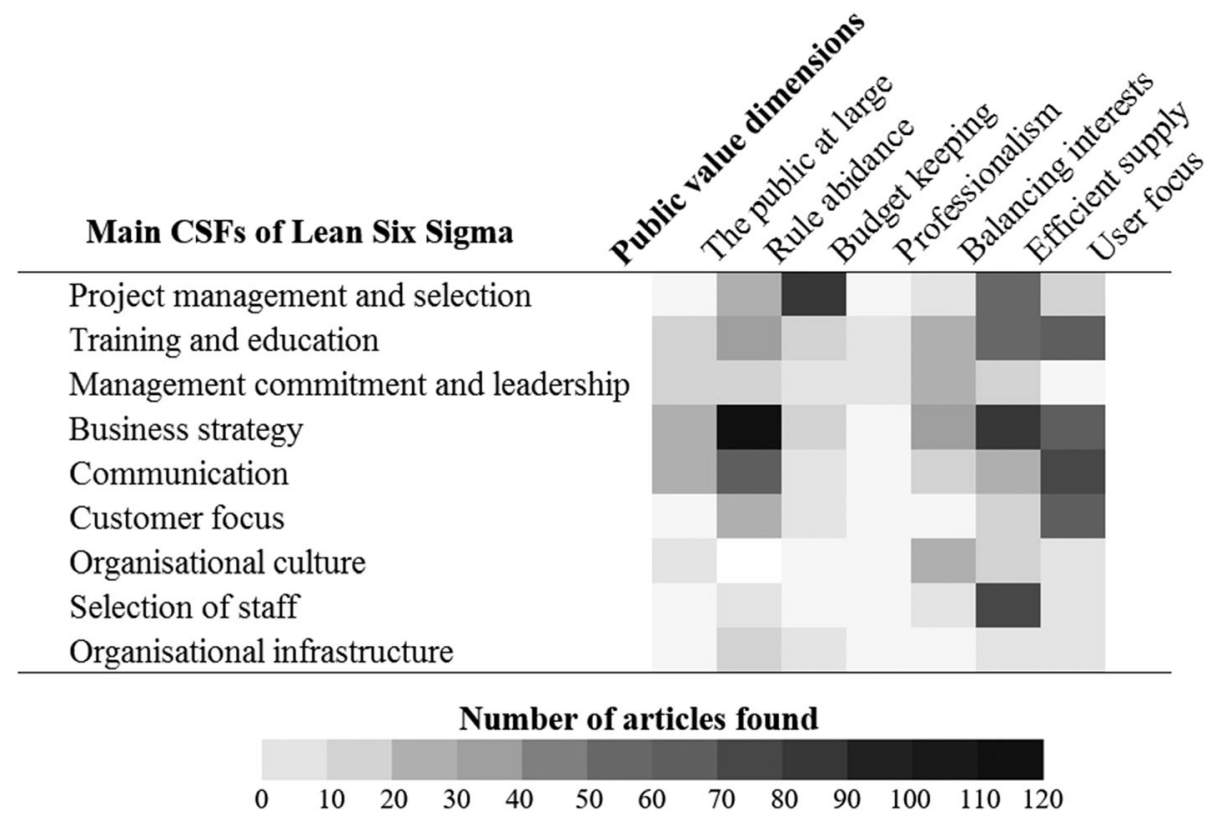

Figure 2. Density map of possible synergies between the two approaches.

this study are due to the greater number of articles found, suggesting the higher probability that there are synergies between the critical factor of LSS and the public value.

\subsection{Business strategy and rule abidance}

In the context of waste management in the European industry, Costa, Massard, and Agarwal (2010) believe that policy and legislation can positively influence the development of industrial symbiosis, setting clear objectives and supporting the activities that generate business efficiency. The results of another study carried out by ElTayeb, Zailani, and Jayaraman (2010) show that regulations have positive effects on the process of green purchasing (initiative that tries to ensure that purchased products meet environmental objectives) in the Malaysian manufacturing sector. Peterson (2013) believes that legal mechanisms can be used as a strategic tool for business to achieve competitive advantage and suggest the use of a manager's legal plan to address and prevent legal violations, and encouraging the perception of legal issues as business opportunities.

\subsection{Project management and budget keeping}

According to Stevenson and Starkweather (2010), the increasing risk of failure in costly projects has led industry and universities to investigate and identify the critical factors for successful project implementation. Specifically, in the construction industry, Chou (2011) states that when the proposed budget is less than the cost required, planned construction may be delayed or may not meet expectations. If the proposed budget significantly exceeds the actual cost requirements, the budget may be idle, denying funds to other major construction projects. In another study, Reich, Gemino, and Sauer (2014) 
showed that the project budget is not adversely affected when special attention is given to knowledge management. Wibowo and Kochendoerfer (2011) present a methodology for selecting projects in the context of Indonesia's infrastructure industry which brings the government less fiscal risk for a given budget constraint.

\subsection{Business strategy and efficient supply}

Demeter, Chikán, and Matyusz (2011) present in their study significant correlations between changes in labour productivity and business performance changes, and state that the growth of total productivity can be an important factor for business success. Escribano and Stucchi (2013) studied the evolution of the productivity of Spanish manufacturing companies during the period 1991-2005 and its relationship with the business cycle. In their analysis on information technology (IT) service industries, Chou and Shao (2014) observed that productivity growth in this sector is mainly driven by technological progress based on innovation, whereas changes in the economy affect negatively productivity in most of the countries studied.

\subsection{Communication and user focus}

In the study carried out by Steckenreuter and Wolf (2013), the use of persuasive messages based on both behavioural and normative beliefs proved to be a very effective tool to encourage visitors to pay a park user fee, since it reduced the rejection by almost $50 \%$. Wong and Lam (2011) point out synergies between communication and end user, and address the interaction of end users with electronic information exchange systems, emphasising the difficulties and obstacles in using these technologies. Bao and Chang (2014) also address the importance of technology for the communication between companies and clients through the use of electronic word of mouth in the marketing campaigns for product sales.

\subsection{Selection of staff and efficient supply}

Iverson and Zatzick (2011) observed that organisations showing greater consideration for employees' morale and welfare in the downsizing process experience were more productive. In their study, Bapna, Langer, Mehra, Gopal, and Gupta (2013) investigated the impact of investments in human capital made by a large company of Indian IT services on employee performance, concluding that additional training leads to a significant increase in performance. Finally, Shafer and Moeller (2012) investigated the impact of Six Sigma adoption on corporate performance and concluded that Six Sigma positively impacts organisational performance primarily through the efficiency with which employees are deployed.

\section{Conclusions}

This article presented some synergies across CSFs of LSS and PVs introduced into public service management based on the nine more relevant CSFs for LSS application and the seven PVs dimensions. This analysis was intended to point out where at least four relevant CSFs of LSS overlap four significant public value dimensions. Business strategy, related to main CSFs of LSS, and efficient supply, linked to public value dimensions, can be highlighted because both were in the most cited group twice. 
It was possible to identify five synergies between CSFs of LSS and PVs: business strategy with rule abidance (i.e. using legal mechanisms as a strategic tool for business to achieve competitive advantage); project management with budget keeping (i.e. creating a methodology for selecting projects which brings the government less fiscal risk for a given budget constraint); business strategy with efficient supply (i.e. enabling productivity growth being mainly driven by technological progress based on innovation); communication with user focus (i.e. using technology for better communication between companies and clients) and selection of staff with efficient supply (i.e. investing in human capital, concluding that additional training leads to a significant increase in performance).

The analysis is not exhaustive, it sought to point out where there may be synergies between LSS and public sector, highlighting those identified in most cited articles based on keywords that can present numerous variations and synonyms not used in the analysis, which suggests there are synergies between CSFs of LSS and VPs not presented in this paper. However, the identification of some synergies leaves the field open to further investigations and can encourage researchers and public managers interested in LSS application in the public sector to identify synergies which have not been presented yet and to increase knowledge of those already known. This research should assist public managers of adopting the LSS practice, and guide researchers in the development of surveys aimed at the application of this methodology in public organisations in general, enabling a better quality of services provided to citizens.

\section{Disclosure statement}

No potential conflict of interest was reported by the authors.

\section{References}

Andersen, L. B., Jørgensen, T. B., Kjeldsen, A. M., Pedersen, L. H., \& Vrangbaek, K. (2013). Public values and public service motivation: Conceptual and empirical relationships. The American Review of Public Administration, 43(3), 292-311. doi:10.1177/0275074012440031

Andersen, L. B., Jørgensen, T. B., Kjeldsen, A. M., Pedersen, L. H., \& Vrangbæk, K. (2012). Public value dimensions: Developing and testing a multi-dimensional classification. International Journal of Public Administration, 35(11), 715-728. doi:10.1080/01900692.2012.670843

Antony, J., Krishan, N., Cullen, D., \& Kumar, M. (2012). Lean Six Sigma for higher education institutions (HEIs). International Journal of Productivity and Performance Management, 61(8), 940-948. doi:10.1108/17410401211277165

Assarlind, M., \& Aaboen, L. (2014). Forces affecting one Lean Six Sigma adoption process. International Journal of Lean Six Sigma, 5(3), 324-340. Retrieved from http:// publications.lib.chalmers.se/publication/195135-forces-affecting-one-lean-six-sigmaadoption-process doi:10.1108/IJLSS-07-2013-0039

Assarlind, M., Gremyr, I., \& Bäckman, K. (2013). Multi-faceted views on a Lean Six Sigma application. International Journal of Quality \& Reliability Management, 30(4), 387-402. https:// doi.org/10.1108/02656711311308385

Aurich, J. C., Mannweiler, C., \& Schweitzer, E. (2010). How to design and offer services successfully. CIRP Journal of Manufacturing Science and Technology, 2(3), 136-143. doi:10.1016/j. cirpj.2010.03.002

Bakar, F. A. A., Subari, K., \& Daril, M. A. M. (2015). Critical success factors of Lean Six Sigma deployment: A current review. International Journal of Lean Six Sigma, 6(4), 339-348. doi:10.1108/IJLSS-04-2015-0011

Bannister, F., \& Connolly, R. (2014). ICT, public values and transformative government: A framework and programme for research. Government Information Quarterly, 31, 119-128. doi:10. 1016/j.giq.2013.06.002 
Bao, T., \& Chang, T. L. S. (2014). Finding disseminators via electronic word of mouth message for effective marketing communications. Decision Support Systems, 67, 21-29. doi:10.1016/j. dss.2014.07.006

Bapna, R., Langer, N., Mehra, A., Gopal, R., \& Gupta, A. (2013). Human capital investments and employee performance: An analysis of IT services industry. Management Science, 59(3), 641-658. doi:10.1287/mnsc. 1120.1586

Bilouseac, I., Zaharia, P., \& Scutariu, A. L. (2012). Comparative aspects regarding the management of Swiss and Romanian local public services: Neuchatel and Suceava cases. Procedia Economics and Finance, 3(12), 1024-1029. doi:10.1016/S2212-5671(12)00268-7

Bruns, H.-J. (2014). Accounting change and value creation in public services - Do relational archetypes make a difference in improving public service performance? Critical Perspectives on Accounting, 25(4-5), 339-367. doi:10.1016/j.cpa.2013.05.005

Bryson, J. M., Crosby, B. C., \& Bloomberg, L. (2014). Public value governance: Moving beyond traditional public administration and the new public management. Public Administration Review, 74(4), 445-456. doi:10.1111/puar.12238

Cheng, C.-Y., \& Chang, P.-Y. (2012). Implementation of the Lean Six Sigma framework in nonprofit organisations: A case study. Total Quality Management \& Business Excellence, 23(3-4), 431-447. doi:10.1080/14783363.2012.663880

Chou, J. S. (2011). Cost simulation in an item-based project involving construction engineering and management. International Journal of Project Management, 29(6), 706-717. doi:10.1016/j. ijproman.2010.07.010

Chou, Y.-C., \& Shao, B. B. M. (2014). Total factor productivity growth in information technology services industries: A multi-theoretical perspective. Decision Support Systems, 62, 106-118. doi:10.1016/j.dss.2014.03.009

Conteh, C. (2012). Public management in an age of complexity: Regional economic development in Canada. International Journal of Public Sector Management, 25(6), 464-472. doi:10.1108/ 09513551211260649

Costa, I., Massard, G., \& Agarwal, A. (2010). Waste management policies for industrial symbiosis development: Case studies in European countries. Journal of Cleaner Production, 18(8), 815-822. doi:10.1016/j.jclepro.2009.12.019

Cuadrado-Ballesteros, B., García-Sánchez, I.-M., \& Prado-Lorenzo, J.-M. (2012). Effects of different modes of local public services delivery on quality of life in Spain. Journal of Cleaner Production, 37, 68-81. doi:10.1016/j.jclepro.2012.06.008

de Graaf, G., Huberts, L., \& Smulders, R. (2014). Coping with public value conflicts. Administration \& Society, 1-27. doi:10.1177/0095399714532273

Demeter, K., Chikán, A., \& Matyusz, Z. (2011). Labour productivity change: Drivers, business impact and macroeconomic moderators. International Journal of Production Economics, 131(1), 215-223. doi:10.1016/j.ijpe.2010.11.003

Duarte, B., Montgomery, D., Fowler, J., \& Konopka, J. (2012). Deploying LSS in a global enterprise - project identification. International Journal of Lean Six Sigma, 3(3), 187-205. doi:10.1108/ 20401461211282709

ElTayeb, T. K., Zailani, S., \& Jayaraman, K. (2010). The examination on the drivers for green purchasing adoption among EMS 14001 certified companies in Malaysia. Journal of Manufacturing Technology Management, 21(2), 206-225. doi:10.1108/17410381011014378

Escribano, Á, \& Stucchi, R. (2013). Does recession drive convergence in firms' productivity? Evidence from Spanish manufacturing firms. Journal of Productivity Analysis, 1-11. doi:10.1007/s11123-013-0368-5

Gonzalez, E., Carcaba, A., Ventura, J., \& Garcia, J. (2011). Measuring quality of life in Spanish municipalities. Local Government Studies, 37(2), 171-197. doi:10.1080/03003930.2011. 554826

Hilton, R. J., \& Sohal, A. (2012). A conceptual model for the successful deployment of Lean Six Sigma. International Journal of Quality \& Reliability Management, 29(1), 54-70. doi:10. $1108 / 02656711211190873$

Iverson, R. D., \& Zatzick, C. D. (2011). The effects of downsizing on labor productivity: The value of showing consideration for employees' morale and welfare in high-performance work systems. Human Resource Management, 50(1), 29-44. doi:10.1002/hrm.20407 
Jeyaraman, K., \& Teo, L. K. (2010). A conceptual framework for critical success factors of Lean Six Sigma: Implementation on the performance of electronic manufacturing service industry. International Journal of Lean Six Sigma, 1(3), 191-215. doi:10.1108/20401461011075008

Jørgensen, T. B., \& Rutgers, M. R. (2015). Public values: Core or confusion? Introduction to the centrality and puzzlement of public values research. The American Review of Public Administration, 45(1), 3-12. doi:10.1177/0275074014545781

Jørgensen, T. B., \& Sørensen, D.-L. (2013). Codes of good governance - national or global public values? Public Integrity, 15(1), 71-96. doi:10.2753/PIN1099-9922150104

Laureani, A., \& Antony, J. (2012). Critical success factors for the effective implementation of Lean Sigma: Results from an empirical study and agenda for future research. International Journal of Lean Six Sigma, 3(4), 274-283. doi:10.1108/20401461211284743

Laureani, A., \& Antony, J. (2017). Leadership characteristics for Lean Six Sigma. Total Quality Management \& Business Excellence, 21(3-4), 1-29. doi:10.1080/14783363.2017.1288565

Manville, G., Greatbanks, R., Krishnasamy, R., \& Parker, D. W. (2012). Critical success factors for Lean Six Sigma programmes: A view from middle management. International Journal of Quality and Reliability Management, 29(1), 7-20. doi:10.1108/02656711211190846

Meza, D., \& Jeong, K.-Y. (2013). Measuring efficiency of Lean Six Sigma project implementation using data envelopment analysis at NASA. Journal of Industrial Engineering and Management, 6(2), 401-422. doi:10.3926/jiem.582

Parris, A. (2013). Improving processes for good in east Africa. The TQM Journal, 25(5), 458-472. doi:10.1108/TQM-11-2012-0101

Peterson, E. A. (2013). Compliance and ethics programs: Competitive advantage through the law. Journal of Management and Governance, 17(4), 1027-1045. doi:10.1007/s10997-0129212-y

Psychogios, A. G., Atanasovski, J., \& Tsironis, L. K. (2012). Lean Six Sigma in a service context: A multi-factor application approach in the telecommunications industry. International Journal of Quality \& Reliability Management, 29(1), 122-139. doi:10.1108/02656711211190909

Psychogios, A. G., \& Tsironis, L. K. (2012). Towards an integrated framework for Lean Six Sigma application: Lessons from the airline industry. Total Quality Management and Business Excellence, 23(3-4), 397-415. Retrieved from http://www.scopus.com/inward/record.url? eid=2-s2.0-84860175007\&partnerID=tZOtx3y1 doi:10.1080/14783363.2011.637787

Reich, B. H., Gemino, A., \& Sauer, C. (2014). How knowledge management impacts performance in projects: An empirical study. International Journal of Project Management, 32(4), 590-602. doi:10.1016/j.ijproman.2013.09.004

Shafer, S. M., \& Moeller, S. B. (2012). The effects of Six Sigma on corporate performance: An empirical investigation. Journal of Operations Management, 30(7-8), 521-532. doi:10. 1016/j.jom.2012.10.002

Shahin, A., Attafar, A., \& Samea, M. (2012). An integrated approach for service quality and effectiveness improvement with a case study in the recycling pavilion service process of Isfahan municipality. Measuring Business Excellence, 16(3), 84-99. doi:10.1108/ 13683041211257439

Steckenreuter, A., \& Wolf, I. D. (2013). How to use persuasive communication to encourage visitors to pay park user fees. Tourism Management, 37, 58-70. doi:10.1016/j.tourman.2013.01.010

Stevenson, D. H., \& Starkweather, J. A. (2010). PM critical competency index: IT execs prefer soft skills. International Journal of Project Management, 28(7), 663-671. doi:10.1016/j. ijproman.2009.11.008

Tenera, A., \& Pinto, L. C. (2014). A Lean Six Sigma (LSS) project management improvement model. Procedia - Social and Behavioral Sciences, 119, 912-920. doi:10.1016/j.sbspro. 2014.03.102

Timans, W., Ahaus, K., van Solingen, R., Kumar, M., \& Antony, J. (2014). Implementation of continuous improvement based on Lean Six Sigma in small- and medium-sized enterprises. Total Quality Management \& Business Excellence, (November), 1-16. doi:10.1080/14783363. 2014.980140

Timans, W., Antony, J., Ahaus, K., \& van Solingen, R. (2012). Implementation of Lean Six Sigma in small and medium-sized manufacturing enterprises in the Netherlands. Journal of the Operational Research Society, 63(3), 339-353. doi:10.1057/jors.2011.47

Tukker, A. (2013). Product services for a resource-efficient and circular economy - a review. Journal of Cleaner Production, doi:10.1016/j.jclepro.2013.11.049 
Van der Wal, Z., Nabatchi, T., \& de Graaf, G. (2014). From galaxies to universe. The American Review of Public Administration, 45(1), 13-28. doi:10.1177/0275074013488822

Wang, F. K., \& Chen, K. S. (2012). Application of Lean Six Sigma to a panel equipment manufacturer. Total Quality Management \& Business Excellence, 23(3-4), 417-429. doi:10.1080/ 14783363.2011.593876

Wibowo, A., \& Kochendoerfer, B. (2011). Selecting BOT/PPP infrastructure projects for Government Guarantee Portfolio under conditions of budget and risk in the Indonesian context. Journal of Construction Engineering and Management, 137(7), 512-522. doi:10. 1061/(ASCE)CO.1943-7862.0000312

Wong, F. W. H., \& Lam, P.T. I. (2011). Difficulties and hindrances facing end users of electronic information exchange systems in design and construction. Journal of Management in Engineering, 27(1), 28-39. doi:10.1061/(ASCE)ME.1943-5479.0000028

\section{Appendix}

\section{Appendix - queries performed in the Scopus database}

\section{Projects management/selection and public value dimensions}

(KEY ('project management') OR KEY ('project selection') AND KEY (accountability) OR KEY (transparency)) AND DOCTYPE (ar) AND PUBYEAR > 2009 AND PUBYEAR < 2016 AND (LIMIT-TO (LANGUAGE, 'English')) AND (LIMIT-TO (SUBJAREA, 'BUSI'))

(KEY ('project management') OR KEY ('project selection') AND KEY (rule) OR KEY (law)) AND DOCTYPE (ar) AND PUBYEAR > 2009 AND PUBYEAR < 2016 AND (LIMIT-TO (LANGUAGE, 'English')) AND (LIMIT-TO (SUBJAREA, 'BUSI'))

(KEY ('project management') OR KEY ('project selection') AND KEY (budget)) AND DOCTYPE (ar) AND PUBYEAR > 2009 AND PUBYEAR < 2016 AND (LIMIT-TO (LANGUAGE, 'English')) AND (LIMIT-TO (SUBJAREA, 'BUSI'))

(KEY ('project management') OR KEY ('project selection') AND KEY (professionalism)) AND DOCTYPE (ar) AND PUBYEAR > 2009 AND PUBYEAR < 2016 AND (LIMIT-TO (LANGUAGE, 'English')) AND (LIMIT-TO (SUBJAREA, 'BUSI'))

(KEY ('project management') OR KEY ('project selection') AND KEY (interest) OR KEY (politics)) AND DOCTYPE (ar) AND PUBYEAR $>2009$ AND PUBYEAR $<2016$ AND (LIMIT-TO (LANGUAGE, 'English')) AND (LIMIT-TO (SUBJAREA, 'BUSI'))

(KEY ('project management') OR KEY ('project selection') AND KEY (productivity)) AND DOCTYPE (ar) AND PUBYEAR > 2009 AND PUBYEAR < 2016 AND (LIMIT-TO (LANGUAGE, 'English')) AND (LIMIT-TO (SUBJAREA, 'BUSI'))

(KEY ('project management') OR KEY ('project selection') AND KEY (user)) AND DOCTYPE (ar) AND PUBYEAR > 2009 AND PUBYEAR < 2016 AND (LIMIT-TO (LANGUAGE, 'English')) AND (LIMIT-TO (SUBJAREA, 'BUSI'))

Training/ education and public value dimensions

(KEY (training) OR KEY (education) AND KEY (accountability) OR KEY (transparency)) AND DOCTYPE (ar) AND PUBYEAR > 2009 AND PUBYEAR < 2016 AND (LIMIT-TO

(LANGUAGE, 'English')) AND (LIMIT-TO (SUBJAREA, 'BUSI'))

(KEY (training) OR KEY (education) AND KEY(rule) OR KEY(law)) AND DOCTYPE(ar) AND PUBYEAR > 2009 AND PUBYEAR < 2016 AND (LIMIT-TO(LANGUAGE,'English')) AND (LIMIT-TO(SUBJAREA, 'BUSI'))

(KEY (training) OR KEY (education) AND KEY (budget)) AND DOCTYPE (ar) AND PUBYEAR $>2009$ AND PUBYEAR < 2016 AND (LIMIT-TO (LANGUAGE, 'English')) AND (LIMITTO (SUBJAREA, 'BUSI'))

(KEY (training) OR KEY (education) AND KEY (professionalism)) AND DOCTYPE (ar) AND PUBYEAR > 2009 AND PUBYEAR < 2016 AND (LIMIT-TO (LANGUAGE, 'English')) AND (LIMIT-TO (SUBJAREA, 'BUSI'))

(KEY (training) OR KEY (education) AND KEY (interest) OR KEY (politics)) AND DOCTYPE (ar) AND PUBYEAR > 2009 AND PUBYEAR < 2016 AND (LIMIT-TO (LANGUAGE, 'English')) AND (LIMIT-TO (SUBJAREA, 'BUSI')) 
(KEY (training) OR KEY (education) AND KEY (productivity)) AND DOCTYPE (ar) AND PUBYEAR > 2009 AND PUBYEAR < 2016 AND (LIMIT-TO (LANGUAGE, 'English')) AND (LIMIT-TO (SUBJAREA, 'BUSI'))

(KEY (training) OR KEY (education) AND KEY (user)) AND DOCTYPE (ar) AND PUBYEAR > 2009 AND PUBYEAR < 2016 AND (LIMIT-TO (LANGUAGE, 'English')) AND (LIMIT-TO (SUBJAREA, 'BUSI'))

Management commitment/ leadership and public value dimensions

(KEY (commitment) OR KEY (leadership) AND KEY (accountability) OR KEY (transparency)) AND DOCTYPE (ar) AND PUBYEAR > 2009 AND PUBYEAR < 2016 AND (LIMIT-TO (LANGUAGE, 'English')) AND (LIMIT-TO (SUBJAREA, 'BUSI'))

(KEY (commitment) OR KEY (leadership) AND KEY (rule) OR KEY (law)) AND DOCTYPE (ar) AND PUBYEAR > 2009 AND PUBYEAR $<2016$ AND (LIMIT-TO (LANGUAGE, 'English')) AND (LIMIT-TO (SUBJAREA, 'BUSI'))

(KEY (commitment) OR KEY (leadership) AND KEY (budget)) AND DOCTYPE (ar) AND PUBYEAR > 2009 AND PUBYEAR < 2016 AND (LIMIT-TO (LANGUAGE, 'English')) AND (LIMIT-TO (SUBJAREA, 'BUSI'))

(KEY (commitment) OR KEY (leadership) AND KEY (professionalism)) AND DOCTYPE (ar) AND PUBYEAR > 2009 AND PUBYEAR $<2016$ AND (LIMIT-TO (LANGUAGE, 'English')) AND (LIMIT-TO (SUBJAREA, 'BUSI'))

(KEY (commitment) OR KEY (leadership) AND KEY (interest) OR KEY (politics)) AND DOCTYPE (ar) AND PUBYEAR > 2009 AND PUBYEAR < 2016 AND (LIMIT-TO (LANGUAGE, 'English')) AND (LIMIT-TO (SUBJAREA, 'BUSI'))

(KEY (commitment) OR KEY (leadership) AND KEY (productivity)) AND DOCTYPE (ar) AND PUBYEAR > 2009 AND PUBYEAR < 2016 AND (LIMIT-TO (LANGUAGE, 'English')) AND (LIMIT-TO (SUBJAREA, 'BUSI'))

(KEY (commitment) OR KEY (leadership) AND KEY (user)) AND DOCTYPE (ar) AND PUBYEAR > 2009 AND PUBYEAR < 2016 AND (LIMIT-TO (LANGUAGE, 'English')) AND (LIMIT-TO (SUBJAREA, 'BUSI'))

\section{Business strategy and public value dimensions}

(KEY (business) AND KEY (accountability) OR KEY (transparency)) AND DOCTYPE (ar) AND PUBYEAR > 2009 AND PUBYEAR < 2016 AND (LIMIT-TO (LANGUAGE, 'English')) AND (LIMIT-TO (SUBJAREA, 'BUSI'))

(KEY (business) AND KEY (rule) OR KEY (law)) AND DOCTYPE (ar) AND PUBYEAR > 2009 AND PUBYEAR < 2016 AND (LIMIT-TO (LANGUAGE, 'English')) AND (LIMIT-TO (SUBJAREA, 'BUSI'))

(KEY (business) AND KEY (budget)) AND DOCTYPE (ar) AND PUBYEAR > 2009 AND PUBYEAR < 2016 AND (LIMIT-TO (LANGUAGE, 'English')) AND (LIMIT-TO (SUBJAREA, 'BUSI'))

(KEY (business) AND KEY (professionalism)) AND DOCTYPE (ar) AND PUBYEAR > 2009 AND PUBYEAR < 2016 AND (LIMIT-TO (LANGUAGE, 'English')) AND (LIMIT-TO (SUBJAREA, 'BUSI'))

(KEY (business) AND KEY (interest) OR KEY (politics)) AND DOCTYPE (ar) AND PUBYEAR $>2009$ AND PUBYEAR < 2016 AND (LIMIT-TO (LANGUAGE, 'English')) AND (LIMITTO (SUBJAREA, 'BUSI'))

(KEY (business) AND KEY (productivity)) AND DOCTYPE (ar) AND PUBYEAR > 2009 AND PUBYEAR < 2016 AND (LIMIT-TO (LANGUAGE, 'English')) AND (LIMIT-TO (SUBJAREA, 'BUSI'))

(KEY (business) AND KEY (user)) AND DOCTYPE (ar) AND PUBYEAR > 2009 AND PUBYEAR < 2016 AND (LIMIT-TO (LANGUAGE, 'English')) AND (LIMIT-TO (SUBJAREA, 'BUSI'))

\section{Communication and public value dimensions}

(KEY (communication) AND KEY (accountability) OR KEY (transparency)) AND DOCTYPE (ar) AND PUBYEAR > 2009 AND PUBYEAR $<2016$ AND (LIMIT-TO (LANGUAGE, 'English')) AND (LIMIT-TO (SUBJAREA, 'BUSI'))

(KEY (communication) AND KEY (rule) OR KEY (law)) AND DOCTYPE (ar) AND PUBYEAR 
$>2009$ AND PUBYEAR < 2016 AND (LIMIT-TO (LANGUAGE, 'English')) AND (LIMITTO (SUBJAREA, 'BUSI'))

(KEY (communication) AND KEY (budget)) AND DOCTYPE (ar) AND PUBYEAR > 2009 AND PUBYEAR < 2016 AND (LIMIT-TO (LANGUAGE, 'English')) AND (LIMIT-TO (SUBJAREA, 'BUSI'))

(KEY (communication) AND KEY (professionalism)) AND DOCTYPE (ar) AND PUBYEAR > 2009 AND PUBYEAR < 2016 AND (LIMIT-TO (LANGUAGE, 'English')) AND (LIMIT-TO (SUBJAREA, 'BUSI'))

(KEY (communication) AND KEY (interest) OR KEY (politics)) AND DOCTYPE (ar) AND PUBYEAR > 2009 AND PUBYEAR < 2016 AND (LIMIT-TO (LANGUAGE, 'English')) AND (LIMIT-TO (SUBJAREA, 'BUSI'))

(KEY (communication) AND KEY (productivity)) AND DOCTYPE (ar) AND PUBYEAR $>2009$ AND PUBYEAR < 2016 AND (LIMIT-TO (LANGUAGE, 'English')) AND (LIMIT-TO (SUBJAREA, 'BUSI'))

(KEY (communication) AND KEY (user)) AND DOCTYPE (ar) AND PUBYEAR > 2009 AND PUBYEAR < 2016 AND (LIMIT-TO (LANGUAGE, 'English')) AND (LIMIT-TO (SUBJAREA, 'BUSI'))

Customer focus and public value dimensions

(KEY (customer) AND KEY (accountability) OR KEY (transparency)) AND DOCTYPE (ar) AND PUBYEAR > 2009 AND PUBYEAR < 2016 AND (LIMIT-TO (LANGUAGE, 'English')) AND (LIMIT-TO (SUBJAREA, 'BUSI'))

(KEY (customer) AND KEY (rule) OR KEY (law)) AND DOCTYPE (ar) AND PUBYEAR > 2009 AND PUBYEAR < 2016 AND (LIMIT-TO (LANGUAGE, 'English')) AND (LIMIT-TO (SUBJAREA, 'BUSI'))

(KEY (customer) AND KEY (budget)) AND DOCTYPE (ar) AND PUBYEAR > 2009 AND PUBYEAR < 2016 AND (LIMIT-TO (LANGUAGE, 'English')) AND (LIMIT-TO (SUBJAREA, 'BUSI'))

(KEY (customer) AND KEY (professionalism)) AND DOCTYPE (ar) AND PUBYEAR > 2009 AND PUBYEAR < 2016 AND (LIMIT-TO (LANGUAGE, 'English')) AND (LIMIT-TO (SUBJAREA, 'BUSI'))

(KEY (customer) AND KEY (interest) OR KEY (politics)) AND DOCTYPE (ar) AND PUBYEAR $>2009$ AND PUBYEAR < 2016 AND (LIMIT-TO (LANGUAGE, 'English')) AND (LIMITTO (SUBJAREA, 'BUSI'))

(KEY (customer) AND KEY (productivity)) AND DOCTYPE (ar) AND PUBYEAR > 2009 AND PUBYEAR < 2016 AND (LIMIT-TO (LANGUAGE, 'English')) AND (LIMIT-TO (SUBJAREA, 'BUSI'))

(KEY (customer) AND KEY (user)) AND DOCTYPE (ar) AND PUBYEAR > 2009 AND PUBYEAR < 2016 AND (LIMIT-TO (LANGUAGE, 'English')) AND (LIMIT-TO (SUBJAREA, 'BUSI'))

Organisational culture and public value dimensions

(KEY (culture) AND KEY (accountability) OR KEY (transparency)) AND DOCTYPE (ar) AND PUBYEAR > 2009 AND PUBYEAR < 2016 AND (LIMIT-TO (LANGUAGE, 'English')) AND (LIMIT-TO (SUBJAREA, 'BUSI'))

(KEY (culture) AND KEY (rule) OR KEY (law)) AND DOCTYPE (ar) AND PUBYEAR > 2009 AND PUBYEAR < 2016 AND (LIMIT-TO (LANGUAGE, 'English')) AND (LIMIT-TO (SUBJAREA, 'BUSI'))

(KEY (culture) AND KEY (budget)) AND DOCTYPE (ar) AND PUBYEAR > 2009 AND PUBYEAR < 2016 AND (LIMIT-TO (LANGUAGE, 'English')) AND (LIMIT-TO (SUBJAREA, 'BUSI'))

(KEY (culture) AND KEY (professionalism)) AND DOCTYPE (ar) AND PUBYEAR > 2009 AND PUBYEAR < 2016 AND (LIMIT-TO (LANGUAGE, 'English')) AND (LIMIT-TO (SUBJAREA, 'BUSI'))

(KEY (culture) AND KEY (interest) OR KEY (politics)) AND DOCTYPE (ar) AND PUBYEAR > 2009 AND PUBYEAR < 2016 AND (LIMIT-TO (LANGUAGE, 'English')) AND (LIMIT-TO (SUBJAREA, 'BUSI'))

(KEY (culture) AND KEY (productivity)) AND DOCTYPE (ar) AND PUBYEAR > 2009 AND 
PUBYEAR < 2016 AND (LIMIT-TO (LANGUAGE, 'English')) AND (LIMIT-TO (SUBJAREA, 'BUSI'))

(KEY (culture) AND KEY (user)) AND DOCTYPE (ar) AND PUBYEAR > 2009 AND PUBYEAR $<2016$ AND (LIMIT-TO (LANGUAGE, 'English')) AND (LIMIT-TO (SUBJAREA, 'BUSI'))

\section{Selection of staff and public value dimensions}

(KEY (staff) OR KEY (employees) AND KEY (accountability) OR KEY (transparency)) AND DOCTYPE (ar) AND PUBYEAR > 2009 AND PUBYEAR < 2016 AND (LIMIT-TO (LANGUAGE, 'English')) AND (LIMIT-TO (SUBJAREA, 'BUSI'))

(KEY (staff) OR KEY (employees) AND KEY (rule) OR KEY (law)) AND DOCTYPE (ar) AND PUBYEAR > 2009 AND PUBYEAR < 2016 AND (LIMIT-TO (LANGUAGE, 'English')) AND (LIMIT-TO (SUBJAREA, 'BUSI'))

(KEY (staff) OR KEY (employees) AND KEY (budget)) AND DOCTYPE (ar) AND PUBYEAR > 2009 AND PUBYEAR < 2016 AND (LIMIT-TO (LANGUAGE, 'English')) AND (LIMIT-TO (SUBJAREA, 'BUSI'))

(KEY (staff) OR KEY (employees) AND KEY (professionalism)) AND DOCTYPE (ar) AND PUBYEAR > 2009 AND PUBYEAR < 2016 AND (LIMIT-TO (LANGUAGE, 'English')) AND (LIMIT-TO (SUBJAREA, 'BUSI'))

(KEY (staff) OR KEY (employees) AND KEY (interest) OR KEY (politics)) AND DOCTYPE (ar) AND PUBYEAR > 2009 AND PUBYEAR $<2016$ AND (LIMIT-TO (LANGUAGE, 'English')) AND (LIMIT-TO (SUBJAREA, 'BUSI'))

(KEY (staff) OR KEY (employees) AND KEY (productivity)) AND DOCTYPE (ar) AND PUBYEAR > 2009 AND PUBYEAR < 2016 AND (LIMIT-TO (LANGUAGE, 'English')) AND (LIMIT-TO (SUBJAREA, 'BUSI'))

(KEY (staff) OR KEY (employees) AND KEY (user)) AND DOCTYPE (ar) AND PUBYEAR > 2009 AND PUBYEAR < 2016 AND (LIMIT-TO (LANGUAGE, 'English')) AND (LIMIT-TO (SUBJAREA, 'BUSI'))

Organisational infrastructure and public value dimensions

(KEY (infrastructure) AND KEY (accountability) OR KEY (transparency)) AND DOCTYPE (ar) AND PUBYEAR $>2009$ AND PUBYEAR $<2016$ AND (LIMIT-TO (LANGUAGE, 'English')) AND (LIMIT-TO (SUBJAREA, 'BUSI'))

(KEY (infrastructure) AND KEY (rule) OR KEY (law)) AND DOCTYPE (ar) AND PUBYEAR > 2009 AND PUBYEAR < 2016 AND (LIMIT-TO (LANGUAGE, 'English')) AND (LIMIT-TO (SUBJAREA, 'BUSI'))

(KEY (infrastructure) AND KEY (budget)) AND DOCTYPE (ar) AND PUBYEAR > 2009 AND PUBYEAR < 2016 AND (LIMIT-TO (LANGUAGE, 'English')) AND (LIMIT-TO (SUBJAREA, 'BUSI'))

(KEY (infrastructure) AND KEY (professionalism)) AND DOCTYPE (ar) AND PUBYEAR > 2009 AND PUBYEAR < 2016 AND (LIMIT-TO (LANGUAGE, 'English')) AND (LIMIT-TO (SUBJAREA, 'BUSI'))

(KEY (infrastructure) AND KEY (interest) OR KEY (politics)) AND DOCTYPE (ar) AND PUBYEAR > 2009 AND PUBYEAR < 2016 AND (LIMIT-TO (LANGUAGE, 'English')) AND (LIMIT-TO (SUBJAREA, 'BUSI'))

(KEY (infrastructure) AND KEY (productivity)) AND DOCTYPE (ar) AND PUBYEAR > 2009 AND PUBYEAR < 2016 AND (LIMIT-TO (LANGUAGE, 'English')) AND (LIMIT-TO (SUBJAREA, 'BUSI'))

(KEY (infrastructure) AND KEY (user)) AND DOCTYPE (ar) AND PUBYEAR > 2009 AND PUBYEAR < 2016 AND (LIMIT-TO (LANGUAGE, 'English')) AND (LIMIT-TO (SUBJAREA, 'BUSI')) 